\section{The Covid-19 Crisis: Retailing and Sustainable Development}

Peter Jones and Daphne Comfort

School of Business, University of

Gloucestershire, Cheltenham, UK

\section{Keywords}

COVID-19 $\cdot$ Crisis $\cdot$ Retailing: sustainable development $\cdot$ Business models

\section{Introduction}

Covid-19 has been described by Kristalina Georgieva, Managing Director of the International Monetary Fund, as "a crisis like no other" (World Economic Forum 2020), and it certainly has had a devastating impact on the global economy. Aside from the wide range of responses from governments around the world, a number of organizations including the International Monetary Fund, the World Bank, and the International Labour Organization have looked to provide policy advice, technical assistance, and financial resources in an attempt to mitigate the worst excesses of the crisis. In introducing its "COVID-19: Response Program," the World Business Council for Sustainable Development
(2020) argued it "was essential to continue our work on sustainable development."

The initial formal definition of sustainable development, namely "development that meets the needs of the present without compromising the ability of future generations to meet their own needs" (World Commission on Environment and Development, 1987), is still widely used over three decades after it was framed. That said, the concept has been extended to more fully recognize its environmental, social, and economic dimensions; to embrace equity across geographical space, as well as over time; to incorporate business imperatives as part of corporate sustainability strategies; and to encompass a wide range of human endeavors and environmental events. Over the last two decades, sustainability strategies and programs have assumed an increasingly high profile within large retail companies, (e.g. Jones, Comfort, \& Hillier 2011; Wiese, Zielke, \& Toporowski 2015). However, COVID-19 has posed a major challenge for many retailers, and there are concerns that they may reduce their commitment to sustainable development.

Emily Salter, an analyst at Globaldata, the data analytics and consulting company, for example, was reported as claiming "making changes to materials, logistics and production processes to improve the sustainability of products and operations will slow, as sustainability is no longer top of retailers' and consumers' agendas" (365Retail 2020). However, a counter argument holds that a continuing commitment to sustainable 
development will be vitally important in maintaining the relationships between retailers and the natural and social capital on which they depends. Sustainable Brands (2020), a global community of brand innovators, advised "consumers will have a renewed interest in protecting humanity against existential risks such as climate change and they will seek leadership in that fight from companies. This is a crucial time for you to anchor your business around environmental responsibility and set yourself apart from your competitors."

Both sides of this argument were captured by Rachel Cernansky (2020), writing under the banner of Vogue Business. On the one hand, she suggested "in a global crisis, retailers across all sectors are forced to cut costs and shift priorities. That pressure can lead to sustainability initiatives being put on the backburner" and that "by conventional calculations, the odds that fashion will continue trying to reduce its environmental impacts in the face of the coronavirus pandemic seem bleak." However, Rachel Cernansky (2020) also claimed "some industry experts think, cautiously, that the challenges of climate change, plastic pollution and workers' well-being are too urgent to ignore, and that sustainability efforts won't be going anywhere. Rather, this can be a moment of re-evaluation and transition for the industry - and that transition, if handled right, can spell opportunity. Whether or not the industry treats it as such will be determined in corporate offices - or executive-level Zoom meetings — in the weeks and months ahead."

With these thoughts in mind, this chapter explores some of the relationships between retailing and sustainable development through the lens of the COVID-19 crisis. The chapter provides an outline of the COVID-19 crisis and of its impact within retailing and explores some of the relationships between retailing and sustainable development. This chapter is not an empirical paper, rather it rehearses some of the arguments about the relationships between retailing and sustainable development as illuminated by the COVID-19 crisis and draws on the views and opinions of a number of authorities on sustainable development within the retail industry. The paper was written in
April 2020, while both the authors were in lockdown, and as such it offers a snapshot in time of their perceptions of sustainable development as illuminated by the COVID-19 crisis, at a very testing time for retailers.

\section{The COVID-19 Crisis}

COVID-19 is an infectious disease caused by SARS-CoV-2, a newly discovered coronavirus. Coronaviruses are part of a large family of viruses that can affect birds and mammals, including humans. In recent years, this family of viruses has been responsible for several outbreaks around the world, including Severe Acute Respiratory Syndrome in 2002-2003 and the Middle East Respiratory Syndrome first reported in South Korea in 2012. COVID-19 primarily affects the lungs and airways leading to mainly respiratory symptoms, for example, a cough and shortness of breath, and fevers. The majority of people with COVID-19 experience mild symptoms of the disease and recover without requiring specialist treatment. However older people, those with underlying medical problems such as cardiovascular disease, diabetes, chronic respiratory disease, and those with a weakened immune system, are more likely to develop serious illness and are at an increased risk of dying from the disease.

The disease can spread from person to person through small droplets from the nose or mouth which are spread when a person with COVID-19 coughs, sneezes, or exhales. These droplets land on objects and surfaces around the person. Other people then catch COVID-19 by touching these objects or surfaces, then touching their eyes, nose, or mouth. People can also catch COVID-19 if they breathe in droplets from a person with COVID-19 who coughs, sneezes, or exhales droplets. Precise details of the origins and initial spread of COVID19 are hard to confirm, but there is some measure of agreement that the disease originated in a wholesale market in Wuhan, a city of some 11 million people, in Eastern China, and that some of the market traders may have contracted the disease following contact with animals at the market. 
On 31 December 2019, China alerted the World Health Organization to several cases of unusual pneumonia in Wuhan, and several of those infected worked at one of the city's markets. Early in 2020, the disease spread rapidly, first to other regions of China, and eventually to the majority of the world's countries, and the World Health Organization declared the global outbreak of COVID-19 a pandemic on 11 March 2020. Though the nature of the response to the crisis has varied from one country to another, all medical authorities and governments have struggled to combat COVID-19. Medical pressures included providing large numbers of bed spaces and specialist equipment to treat seriously ill patients, sufficient numbers of, and personal protection equipment for, medical staff, and adequate testing facilities. The policies adopted by many governments have centered on enforcing social distancing by strongly recommending restrictions on the movement of people, popularly described as lockdown, and instructing many businesses to close down, in an attempt to prevent the spread of the disease.

The COVID-19 crisis has had a wide range of environmental, economic, and social consequences and as such has had a major impact on sustainable development. At the same time, the crisis has identified the need to extend the scope of sustainable development. Here there is the issue of the role of sustainable development in preventing future pandemics, as such events, thankfully relatively rare as they are, have not been included in traditional approaches to sustainable development. Di Marco et al. (2020), for example, observed that "little attention has been paid to the interactions between environmental change and infectious disease emergence" and such interactions are "not customarily integrated into planning for sustainable development." More specifically, Di Marco et al. (2020) claimed that the emergence of diseases "is driven by anthropogenic changes such as deforestation and expansion of agricultural land (i.e., land-use change), intensification of livestock production, and increased hunting and trading of wildlife." Looking to the future, Di Marco et al. (2020) claimed that human health could be more effectively integrated within sustainable development planning but argued this required "a crossdisciplinary research approach," which would involve "socioeconomic change, pathogen dynamics, and biological and behavioral aspects of humans, wildlife, and livestock."

\section{Environmental, Social, and Economic Impacts}

The relationship between retailing and sustainable development, as illuminated by the COVID-19 crisis, can be seen in a number of ways. Initially, a number of environmental improvements were identified including marked reductions in pollution levels and greenhouse gas emissions following the closure of many power generation plants and factories, the dramatic fall in the volume of air travel, and the restrictions on the movement of people in motor vehicles on journeys to work or shopping trips within, and between, towns and cities. However, such improvements will surely not be maintained if/when the economy recovers. Inger Anderson, Head of the United Nations Environment Programme, for example, was reported as arguing "we need to take on board the environmental signals and what they mean for our future and wellbeing because COVID-19 is by no means a silver lining for the environment," and that "visible positive impacts - whether through improved air quality or reduced greenhouse gas emissions are but temporary because they come on the back of tragic economic slowdown and human distress" (United Nations News 2020).

While the COVID-19 crisis has brought some general environmental gains, it has also caused a range of economic and social problems and has had economic and social consequences for sustainable development. Shopping can be a significant element in many people's social lives, all the more so for elderly people and for those who live alone, in that it gives them what is often a welcome opportunity to meet and talk with friends and fellow shoppers. As such the closure of many shops and social distancing recommendations have markedly reduced the social element in shopping and have effectively contributed to 
increasing social exclusion. Economically, the COVID-19 crisis has had a very damaging impact on sectoral economies. In April 2020, the United Nations Department of Economic and Social Affairs (2020) suggested "growing restrictions on the movement of people and lockdowns in Europe and North America are hitting the service sector hard, particularly industries that involve physical interactions such as retail trade, leisure and hospitality, recreation and transportation services."

Within retailing, there have been economic impacts throughout supply chains covering consumer behavior, product demand, store operations, distribution, and production. However, such impacts have not been universally felt across the whole of the retail spectrum, and there have been variations between countries and during the course of the crisis. In most countries, a variety of food shops have - of necessity - continued to trade to enable customers to buy essential foodstuffs, but fashion, furniture, and electronics retailers have followed government instructions to close down temporarily. Ironically, some of the UK's large food retailers have witnessed increased demand due to the public's fears about possible food shortage and to panic buying during the COVID-19 crisis, and they have been employing new staff, albeit temporarily, to help them meet this demand.

Dentons (2020), the international law firm, published and regularly updated, listings of the retail situation in 28 countries, and these listings include details of which types of shops were open and closed, and information on employment support packages, leasing arrangements, and tax rebates. As of 26 April 2020, the UK Government's earlier order to close all retail businesses that sell nonessential retail business was still in place. In practice, shops permitted to open included supermarkets and other food shops; pharmacies and chemists; bicycle shops; hardware shops; corner shops and newsagents; off licenses and licensed shops selling alcohol. At that time, a number of the UK's larger retail chains, including IKEA, Clarks, Body Shop, HMV, Beaverbrooks, The Entertainer, and Waterstones, and the John Lewis, Harvey
Nicholls, Debenhams, and Fenwick department stores, had all temporarily closed.

In Italy, only food stores, supermarkets, and pharmacies were open. In the Netherlands, shops were open as usual though they had to observe responsible shopping protocols, including a minimum of 1.5 meters distance between persons in the store and a maximum of one person per 10 square meters of floor space. In Poland, in shopping centers with more than 2,000 square meters of floorspace, only shops selling essential goods were open, though there were no restrictions on the opening of shops, in smaller shopping centers, subject to social distancing and hygiene measures, though many stores had closed voluntarily. Outside Europe, in Canada only stores that provided essential services were open, though the definition of essential services differed from one province to another. In Australia, food markets, supermarkets, grocery stores, bottle shops selling alcohol, and hairdressers were open. In China, many shops were open, while in Singapore only shops that provided essential services, including supermarkets, convenience stores, grocery retailers, wholesale markets, wet markets, hairdressers, opticians, and pet food supplies stores were open.

In a number of European countries, government measures were in place to prevent permanent redundancies and avoid job losses and to provide income support, but the scale of these measures varied between countries, and in Hungary, for example, workers within the retail sector were not eligible for the support available to other workers. In many countries, small shops owned and run by independent self-employed workers and families were not eligible for government income support packages. More widely outside of Europe and more specifically in many less developed countries, the magnitude of direct and - more significantly - indirect job losses caused by the COVID-19 crisis was much greater. In some of these countries, as for example in India, Kenya, Uganda, and South Africa, retail structures are more informal, and traders, hit by the COVID-19 crisis, have no other income to support themselves and their families. Perhaps more significantly, many of the large retailers in 
Europe and the USA source their goods from producers in less developed countries, and shops' closures in developed countries have had very damaging consequences at the production end of supply chains. This has led to massive job losses, which have thrown many millions of workers and their families into the poverty abyss. Such problems have almost certainly considerably set back the course of sustainable development in many parts of the world.

A small number of European retailers have joined programs formed in an attempt to mitigate some of the economic and social damage caused by the COVID-19 crisis and to plan for a more sustainable post COVID-19 future. Firstly, fashion retailing seems particularly vulnerable to the COVID-19 crisis, not least because it relies so heavily on discretionary spending and has a business model that relies on fast-moving trends. A number of leading European fashion retailers, including $\mathrm{H} \& \mathrm{M}$, Inditex, Primark, and $\mathrm{C} \& \mathrm{~A}$, have endorsed a new cross industry plan to provide urgent financial relief to vulnerable garment factories and workers in response to the COVID19 pandemic. Secondly, two of Europe's leading retailers, H\&M and IKEA, for example, along with Unilever, the transnational consumer goods company, have signed up to an informal Green Recovery Alliance of politicians, trade unions, nongovernmental organizations, and business leaders, launched in April 2020. This alliance focused on sustainability post the COVID-19 crisis and is rooted in the conviction that "the transition to a climate-neutral economy, the protection of biodiversity and the transformation of agri-food systems, all have the potential to rapidly deliver jobs, growth and improve the way of life of all citizens worldwide, and to contribute to building more resilient societies" (GREENRECOVERY 2020). Looking positively to the future, the Green Recovery Alliance claimed "Covid-19 will not make climate change and nature degradation go away. We will not win the fight against Covid-19 without a solid economic response. Let's not oppose those two battles, but let's fight and win them at the same time" (GREENRECOVERY 2020).

\section{Corporate Sustainability Programs}

In recent years, corporate sustainability has assumed increasing importance within the business community, and many of the leading players in the retail industry have pursued sustainability programs designed to incorporate environmental, social, economic, and governance issues into their business strategies (e.g., Jones et al. 2011). However, COVID-19 poses a number of challenges for such programs. On the one hand, such challenges may involve the need to respond to both investors' demands and changes in customers' shopping behaviors. Investors' demands may include promoting long-term reductions in retailers' carbon emissions and pollution levels, greater employment of renewable energy resources, a clearer commitment to waste recycling, and the development of circular economy principles. At the same time, changes in customers' shopping habits during the COVID-19 crisis, including a rise in online food shopping with deliveries being made to customers' homes, a desire to shop more locally, and a general increase in internet shopping may become permanent features of many people's shopping behaviors. All of these changes may, in turn, effectively force changes in retailers' conventional business models.

On the other hand, the COVID-19 crisis will surely reduce the availability of, and access to, capital, and this may, in turn, see available financial resources being targeted on essential core business activities. At the store level, the introduction of thermal imaging technology to screen customers, to increase hygiene, to manage numbers, and to monitor entry and exit points, for example, will come at a cost, and they may also limit footfall and deter shoppers. At the corporate level, extensive, high profile, and costly marketing campaigns designed, for example, to promote retailers' brands and special offers, to re-engage with customers, and to try to ensure that returning customers are provided with high quality experiences, may well take precedence over wider environmental and social agendas within retailers' sustainability strategies and programs. In the light of the COVID-19 crisis, large retailers may also review their approach to supply chain 
management and may look to reduce their dependence on producers and manufacturers in the less developed world, but here again this will entail major changes in current retail business models.

Following the creation of the Sustainable Development Goals in 2015, many leading retailers have responded positively to the United Nations call for businesses to rise to the challenges and opportunities generated by the SDGs. Within the UK, for example, the British Retail Consortium launched its "Better Retail Better World," initiative to mobilize "the retail industry to meet some of the biggest global challenges of the coming decades highlighted by the UN, including modern slavery and decent work, sustainable economic growth, inequalities, climate change and responsible consumption and production" (British Retail Consortium 2018). A total of 26 UK retailers, including Asda, Boots, IKEA, John Lewis Partnership, Kingfisher, Marks \& Spencer, Next, Sainsbury's, and Wilko, signed up to the initiative, which specifically targeted just 5 of the 17 SDGs. As such, the initiative can be seen as a limited, rather than a comprehensive contribution to the achievement of the SDGs. In reviewing the "Better Retail, Better World" program, for example, Jones and Comfort (2019a) suggested there were issues about reconciling the commitment to economic growth with the program's environmental and social goals. More specifically, while Jones and Comfort (2019a) observed that the UK's retail industry was looking to achieve "sustainable economic growth," they expressed concern that neither the British Retail Consortium nor the retailers defined the term, and suggested that the retailers' appetite, and perhaps more importantly, that of their shareholders and investors, to finance commitments to the SDGs remained very much to be seen.

While it remains to be seen how the COVID-19 crisis will impact upon retailers' commitments to the SDGs, the situation is, at best, uncertain. On the one hand, major retailers may well argue that it is only by reopening their businesses and returning to something approaching business as normal; will they have the strength and resources and be in a position to contribute to the achievement of the SDGs during the next decade. In the medium term, this may encourage large companies to push back their existing commitments to the SDGs. On the other hand, in those areas of the less developed world where the need for many of the SDGs focused, for example, on the eradication of poverty and hunger, on the widespread availability of clean water and basic sanitation, and on the promotion of gender equality is greatest, many of the limited gains made since 2015 may well have been lost in the wake of the COVID-19 crisis. Such concerns are surely heightened at a time when the Sustainable Development Solutions Network/Institute for European Environmental Policy (2019) reported that none of the countries within the European Union, let alone the less developed world, were on track to meet their SDG targets.

\section{Internal Contradictions}

More generally, the COVID-19 crisis has served to highlight internal contradictions within the concept of sustainable development. On the one hand, there are the tensions between environmental benefits and wide-ranging economic and, to a lesser extent, social costs of the COVID-19 crisis. On the other hand, there are tensions between economic forces and both environmental and social goals illustrated by some of the leading retailers' commitment to the SDGs. Van der Byl and Slawinski (2015), for example, suggested "corporate sustainability is rife with tensions as firms seek to balance often divergent economic, social and environmental goals." In a study of five leading US retailers, namely, Walmart, Kroger, Walgreen Boots Alliance, Target, and The Home Depot, Jones and Comfort (2019b) suggested that their sustainable development reports were couched within the idiom of continuing growth and business expansion, and that their commitments to pursue sustainable development were being primarily driven by business imperatives. More radically, in addressing both sets of contradictions, Liverman's (2018) concerns that "growth goals cannot be met without sacrificing many environmental ones or that sustainability 
cannot be achieved under the current economic model of capitalism" might be seen to resonate.

At the same time, Pushpam Kumar (2020), Chief Environmental Economist, United Nations Environment Programme, was reported as arguing "the emergence of COVID-19 has underscored the mutually-affective relationship between people and nature," that "we must try to understand and appreciate the limits to which humans can push nature, before the impact is negative," and that "those limits must be embraced by our consumption and production aspiration." Retailing can be seen to be fundamental in any move to sustainable consumption, and there is certainly a growing awareness that retailers have a vital role to play in promoting more sustainable patterns of consumption, not least in that they effectively act as gatekeepers between producers and consumers (Wiese et al. 2015). Indeed, a number of the world's major retail trade associations have emphasized their commitment to sustainable consumption. In Europe, for example, the Retail Forum was launched in 2009 to "exchange best practices on sustainability within the European retail sector and to identify opportunities and barriers that may further or hinder the achievement of sustainable consumption and production" and it claimed that "retailers in Europe are in an exceptional position to promote more sustainable consumption" (European Commission 2019).

In many ways sustainable consumption is elusive, it has no generally agreed definition, and in many ways it is also a contradiction in terms. Indeed, sustainable consumption has been described as "the most obdurate challenge for the sustainable development agenda" (Cohen 2005), while the European Environment Agency (2020) described "unsustainable consumption" as "the mother of all environmental issues." However, the COVID-19 crisis has opened a window on what some advocates see as a more sustainable world. In acknowledging "we are now struggling to anticipate the impacts of COVID-19" as "major financial markets are gyrating and international supply chains are in turmoil," Cohen (2020), for example, pointed out that "while the present situation is being treated as an emergent economic crisis, it merits acknowledging that sustainability scientists and policy makers have implicitly been seeking to achieve over the past decade broadly similar objectives..... in the form of a sustainable consumption transition."

Further, Cohen (2020) argued "while it may seem fanciful and insolent, Covid-19 is an opportunity to reduce over the longer term the prevalence of lifestyle premised on large volumes of energy and material throughput" and concludes "policy makers should work to ensure that the coronavirus outbreak contributes to a sustainable consumption transition." Such a transition would demand major changes in the current business model of the vast majority of large retailers. At the present time, neither the majority of retailers nor their customers seem likely to take such an opportunity, or to have much enthusiasm for policy makers who advocate such a future.

\section{Conclusion}

The Covid-19 crisis has not only posed a range of complex major global challenges for retailers, but it has also exposed some new perspectives in the relationships between retailing and sustainable development. Looking forward, it remains to be seen what the future holds, and how these relationships will be played out. On the one hand, the hope is for a return to some sort of normality, though, at the time of writing, the time scale and the extent of such a return remain very uncertain. However, within such a scenario, many retailers, and their customers, may effectively look to pick up where they left off, as part of a much wider post COVID-19 crisis recovery. Here government and corporate sustainability programs may effectively be put on hold as capital resources are focused on economic recovery. On the other hand, the COVID-19 crisis has opened a window on some of the relationships between retailing and sustainable development, it has signaled some environmental changes that may be central to a transition to a more sustainable future, it has highlighted some of the inherent contradictions within the concept of sustainable development, and it has offered some radical solutions to the challenges 
of sustainability. Whether retailers, large and small, or the vast majority of their customers, will want to recognize the significance of such signals and have any genuine enthusiasm for such solutions remains very much to be seen.

In recent years, the increasing incidence of extreme, but relatively localized, weather events, have often been seen as harbingers of dramatic global climate changes, but such events have been largely, and quickly, forgotten. Some commentators have suggested that it might require a cataclysmic global event to trigger collective, rather than individual self-interest, and to precipitate widespread corporate and consumer action to promote wide ranging action on sustainable development, which will privilege natural and social capital above economic growth. In the past, the majority of the population, particularly in the more developed countries, have quickly been able to put localized river and coastal flooding, typhoons, hurricanes, and wildfires to the back of their minds because their lifestyle seemed secure, and such events did not impinge on their homes and economic well-being. However, the COVID19 crisis may turn out to be that cataclysmic event because it has touched most peoples' everyday lives. In one way or another, directly or indirectly, retailing also touches most people's everyday lives, and, following the COVID-19 crisis, it may ultimately offer the key to the transition to a more sustainable future.

\section{References}

365RETAIL. (2020). COVID-19 pandemic will put sustainability concerns on hold. https://www.365retail.co.uk/ covid-19-pandemic-will-put-sustainability-concernson-hold/. Accessed 16 Apr 2020.

British Retail Consortium (2018) Better Retail Better World. https://brc.org.uk/making-a-difference/priorities/ better-retail-better-world (Accessed 20 April 2020)

Cernansky, R. (2020). Will Covid-19 disrupt fashion's sustainability commitments. https://www.voguebusiness. com/sustainability/will-covid-19-coronavirus-disrupt-fas hions-sustainability-commitments. Accessed 21 Apr 2020.

Cohen, M. J. (2005). Sustainable consumption in national context; An introduction to the symposium. http:// ejournal.nbii.org/archives/vol1 iss 1/0410-008.cohen. htmll. Accessed 7 Sept 2009.
Cohen, M. J. (2020). Does the COVID-19 outbreak mark the onset of a sustainable consumption transition? Sustainability: Science Practice and Policy, 16(1), 1-3.

Dentons (2020). Retail: Country-by-country summary of the impact of the COVID-19 crisis. https://www. dentons.com/en/insights/alerts/2020/march/30/covid19-retail-country-by-country-summary Accessed 26 Apr 2020.

Di Marco, M., Baker, L., Daszak, P., De Barro, P., Eskew, E. A., Godde, C. M., et al. (2020). Opinion: Sustainable development must account for pandemic risk. Proceedings of the National Academy of Sciences of the United States of America. https://www.pnas.org/content/117/ 8/3888. Accessed 13 Apr 2020.

European Commission. (2019). Retail forum. https://ec. europa.eu/environment/industry/retail/index_en.htm. Accessed 20 Apr 2020.

European Environment Agency. (2020). Unsustainable consumption - The mother of all environmental issues? https://www.eea.europa.eu/subscription/eea_mai n_subscription/unsustainable-consumption-2013-themother. Accessed 27 Apr 2020.

GREENRECOVERY. (2020). GREEN RECOVERY. https:// drive.google.com/file/d/1j54QxE-QjhrEHjGb5LrKsHuD AKvv8LUq/view. Accessed 27 Apr 2020.

Jones, P., \& Comfort, D. (2019a). Better retail, better world: A commentary on British retailers and the sustainable development goals. Journal of Public Affairs., 20(1). https://onlinelibrary.wiley.com/doi/abs/10.1002/ pa.1910. Accessed 20 Apr 2020.

Jones, P., \& Comfort, D. (2019b). Business Contributions to Sustainable Development: A Study of Leading US Retailers. Advances in Environmental Studies, 3(1), 132-140.

Jones, P., Comfort, D., \& Hillier, D. (2011). Sustainable development in the global shop window. International Journal of Retail and Distribution Management, 39(4), 256-271.

Kumar, P. (2020). COVID-19 and the nature trade off paradigm. https://www.unenvironment.org/news-and-stories/ story/covid-19-and-nature-trade-paradigm. Accessed 17 Apr 2020.

Liverman, D. (2018). Geographical perspectives on development goals: Constructive engagement and critical perspectives on the MDs ad the SDGs. Dialogue in Human Geography, 8(2), 168-185.

Sustainable Brands. (2020). How to pursue sustainability during Covid-19: A tactical guide for brand professionals. https://sustainablebrands.com/read/walking-thetalk/how-to-pursue-sustainability-during-covid-19-a-tact ical-guide-for-brand-professionals. Accessed 19 Apr 2020.

Sustainable Development Solutions Network/Institute for European Environmental Policy. (2019). European sustainable development report: Towards a strategy for achieving the sustainable development goals in the European Union, 2019. https://s3.amazonaws.com/ sustainabledevelopment.report/2019/2019_europe_ 
sustainable_development_report.pdf. Accessed 11 Mar 2020 .

United Nations Department of Economic and Social Affairs. (2020). Covid-19 likely to shrink global GDP by almost $1 \%$ in 2020. https:/www.un.org/development/desa/en/ news/policy/april-monthly-briefing.html. Accessed 17 Apr 2020.

United Nations News. (2020). First person: COVID-19 is not a silver lining for the climate, says UN Environment Chief. https://news.un.org/en/story/2020/04/1061082. Accessed 17 Apr 2020.

Van der Byl, C. A., \& Slawinski, N. (2015). Embracing tensions in corporate sustainability: A review of research from win-wins and trade-offs to paradoxes and beyond. Organization and Environment, 28(1), 54-79.

Wiese, A., Zielke, S., \& Toporowski, W. (2015). Sustainability in retailing - Research streams and emerging trends. International Journal of Retail and Distribution Management., 43(4/5). https:/www.emerald.com/ insight/content/doi/10.1108/IJRDM-02-2015-0024/full/ html. Accessed 20 Apr 2020.

World Business Council for Sustainable Development. (2020). COVID-19: Response Program. https://www. wbcsd.org/Overview/News-Insights/Insights-from-the-Pr esident/Business-as-unusual-reshaping-the-presentand-the-future. Accessed 29 Apr 2020.

World Commission on Environment and Development (1987). Our Common Future. https://sustainablede velopment.un.org/content/documents/5987our-commonfuture.pdf. Accessed 17 April 2020.

World Economic Forum. (2020). COVID-19: What you need to know about the coronavirus pandemic on 4 April. https://www.weforum.org/agenda/2020/04/covid-19what-to-know-about-the-coronavirus-pandemic-on-4april/. Accessed 6 Apr 2020. 